DOI: $10.17148 /$ IARJSET.2021.8937

\title{
Positive Psychology in English Language Teaching with reference to Sigmund Freud's Psychoanalysis
}

\author{
S. Selvi Chandraghantham MA, M. Phil ${ }^{1}$, Dr. D. Franklin Vaseekaran MA., M.Phil., Ph.D ${ }^{2}$ \\ ${ }^{1}$ Assistant Professor, Department of English, CSI College of Engineering, Ketti, The Nilgiris - Tamilnadu \\ ${ }^{2}$ Assistant Professor, Department of English, Bishop Appasamy College of Arts and Science, Coimbatore - Tamilnadu
}

\begin{abstract}
Second Language Learning has captured the minds of youngsters as it opens roads to different destinations. Learning English as a second language in particular has become a necessity. But, for most of the students from rural background, this is not as easy as it sounds. They face a lot of challenges during the course of learning English as a second language. Some students are under constant stress during this process, and according to the psychologists, the current pandemic scenario has increased the case of depression among students. This depression can also be attributed to some of the false ideas and notions that the students may have from negative influences. Sigmund Freud, a great neurologist and psychologist of his period, has come up with many strategies to overcome anxiety and depression, and these strategies can be used to overcome the anxiety and depression caused during language learning. As it is really important for students to have a positive mindset during language learning, teachers are in dire need to help students to develop positive attitude which can enhance the learning. The Penn Resiliency Program, which has its roots in Sigmund Freud's psychoanalysis, can help students in effectively overcoming the anxiety and depression and travel towards productive language learning. In this Penn Resiliency Program, students are made to adapt coping skills of positive psychology as a counterbalance to the effects of anxiety and depression. In a classroom setting, the students should not be trained to deny the existence of problems, but they can be trained to complement it with positive ideas. With the help of positive psychology, students' attention and thinking can be broadened which can lead to new experiences and learning. It is the prime responsibility of teachers to have a good understanding of the psychological needs of the students and to inculcate in them positive attitude with the help of positive psychology.
\end{abstract}

Key words: Psychology in English Language teaching, Positive Psychology and Language learning, resilience and language learning.

\section{INTRODUCTION}

Second language learning or second language acquisition has become a vital part in the lives of the students recently. Most of the students seek to work abroad and show keen interest in learning English as their second language. Though they show great interest in learning English as a second language, most of them go through a lot of challenges and struggles during this acquisition period. These challenges they face can vary from "inferior complex" to "fear of making mistakes." Most of these challenges or hurdles are psychological-based. The lifestyle of every individual has changed considerably. Students and children are provided with various gadgets that we have not even heard of some 5 years ago. With this sophistication, with this complexity of life rather, students have now started to talk about stress more than the adults.

The prevalence of depression among young people is shockingly high worldwide. Nearly $20 \%$ of youth experience an episode of clinical depression by the end of high school (Lewinsohn et al., 1993). By some estimates depression is about ten times more common now than it was 50 years ago. ${ }^{[1]}$

These challenges were already there and this pandemic of Covid-19 has made it worse. During this pandemic, the usage of the electronic gadgets by the students has increased even more. Researchers have found out that the depression and the anxiety rate have increased in students and they attribute this to the online classes and the uncontrolled usage of the electronic gadgets. 


\section{CHALLENGES FACED BY THE STUDENTS}

Today, there are excellent language teaching methods formulated by scholars and teachers. In spite of using such efficient methods, the desired learning result could not be attained. This is because we fail to understand that there is much more beyond the well-formulated methodologies and tools in English Language Teaching. The teaching has always been teacher-centered like "how well can I teach?" "What effective tools and methods can I use?" "Have I prepared well for the class?" and so on, and in this process, we have always overlooked the thoughts that are lingering in the minds of the students.

Apart from the anxiety and depression caused by the online classes and the electronic gadgets, the students also undergo another kind of anxiety when attempting to learn a second language, which is called as the "Language Anxiety." The students face this language anxiety due to false ideas and notions that they gather from some random online advertisements or the false promises made by some youtubers like "Learn English in 30 days" "Speak English Fluently in 21 days" and " 25 days spoken English classes." English language learning cannot happen in just 25 or 30 days. It is a never-ending process where one learns new things every new day. As we all know, the acquisition of our mother tongue takes at least 3 to 4 years. Similarly, learning a second language is also time-consuming. When students start to learn a second language rather late in life, with the false promises already in their mind, they are rather disappointed and wonder why aren't they learning the language in 25 days and why aren't they making any progress too quickly. Most of the thoughts settle in the unconscious mind and start to affect the behavior of the individual. Now, the students start to have all sorts of doubts like "am I the only one struggling to learn" "if I go in this pace, someone is going to judge me" and so on. As a result, they develop anxiety and get into depression.

\section{PSYCHOANALYSIS - A GREAT TOOL TO ENHANCE EDUCATION}

Psychoanalysis is a field of study which was invented by Sigmund Freud, and he is called as the father of Psychoanalysis. He coined the term Psychoanalysis to refer to the set of psychological theories and therapeutic strategies that he used to treat his patients. He further believed that psychoanalysis has a great scope in the field of education and students would be greatly benefited with the collaboration of education and psychoanalysis.

But there is one topic which I cannot pass over so easily-not however because I understand particularly much about it or have contributed very much to it. Quite the contrary: I have scarcely concerned myself with it at all. I must mention it because it is so exceedingly important, so rich in hope for the future, perhaps the most important of all the activities of analysis. What I am thinking of is the application of psychoanalysis to education, to the upbringing of the next generation. ${ }^{[2]}$

The psychoanalytic therapy does not involve any complicated treatment techniques. Psychoanalysis in other words can be termed as "talk therapy" which is used to explore the thoughts that influence the unconscious mind. The right conversation at the right time can bring out the thoughts of the unconscious. In a classroom setting, a teacher can make use of this talk therapy to bring out the negative thought in the students' mind to create positive emotions. These positive emotions are used to broaden one's attention and thinking and leads to new experiences and new learning. By creating positive emotions, the lingering negative thoughts can be cleared and stress is eliminated. Developing this type of positive emotions with the help of psychoanalysis is called as Positive Psychology.

\section{POSITIVE PSYCHOLOGY - THE MODERN INCARNATION OF PSYCHOANALYSIS}

Positive psychology entitles an individual to be competent in whatever field they want and make them realize that the greatest potential of strength is in the area of the greatest weakness. Some students have the positive psychology already in them and are aware of their caliber which enables them to set their goals a little higher, and this becomes easier for them to achieve their goals. Few students on the other hand are unaware of their abilities and set unrealistic goals and thus fail to reach it.

Positive Psychology aims to help people identify their strengths and to find adaptive niches in the world to make use of them in a win-win way. ${ }^{[3]}$

In positive psychology, the students are trained to not deny the existence of problem, but trained to accept reality. With the help of Positive Psychology various positive emotions can be developed like open-mindedness, creativity, authenticity, self-regulation, gratitude, and hope. Above all, an exceptional resilient mindset can be achieved with the help of Positive Psychology. 
Contrary to the reification of half of our psychic life as "negative" in Positive Psychology, psychoanalysis is about dispelling the fear that our impulses are "negative," and it is, to a large degree, trying to understand the legitimate "positive" [4]

\section{RESILIENCE AS A KEY TO OVERCOME LANGUAGE ANXIETY}

Resilience is the psychological strength and ability to recover from any type of crisis. It can be defined as the positive adaptation that the brain processes during significant challenges or times of adversity. Majority of the students have resilience and are able to tackle the anxiety and depression during language acquisition. These resilient students instead of falling in despair or trying to hide from problems, use healthy coping strategies and recover from the difficult situation.

To deal successfully with stress or trauma we need a well-functioning reward system in which we look forward to good things and maintain an appetite for life. Resilient individuals tend to have this, and are able to respond appropriately to positive and hopeful experiences, and the system involved with producing dopamine is centrally implicated in this. ${ }^{[5]}$

But some students lack this resiliency and are easily de-motivated even by the smallest discouragement and disappointments. This does not mean that these students lack resiliency, but means that they need more external support to become more resilient in order to handle the difficult situation in a more appropriate manner. To help such students, many resiliency programs have been formulated and have been used and have produced tremendous results. One such program is "The Penn Resiliency Program" which was developed in the Pennsylvania University and is an evidence-based program where it has proved to decrease depression among students. The purpose of any resiliency program is to make the individual recognize his strengths and talents, encourage insight, generate optimism, help to develop a sense of direction and a sense of fulfillment, and finally achieve the goal. By developing the above qualities, the individual develops resilience and develops a shield against depression and anxiety. In this program, students are taught on developing flexible thinking skills, extracting positivity from negativity, realizing their unique strengths, and developing a growth mindset. Being resilient does not eliminate or erase problems, but it enables the students to understand the difficult path that they are travelling through, and their psychological frame work allows them to work and develop through these situations and recover for the betterment. Here, teachers should be the external support to help them build the resilience.

Resilience is partly the ability to find strength and something positive in the face of adversity, which is not the same as not having any distress or denying it. ${ }^{[6]}$

As part of the resilient program, teachers can promote positive psychology in the students by first recognizing the negative ideas or notions prevalent in one's mind due to the external negative influences. The next step would be to teach them to evaluate the negative thoughts on the basis of facts. After evaluation of the negative thoughts, a more appropriate explanation on the positive counterpart can be given to develop an optimistic mindset in the students.

\section{CONCLUSION}

Students trust and believe teachers more than anyone else where knowledge is concerned and is inclined on the teachers for their intellectual support. Not all students have enough knowledge about negative influences that can create a negative impact in their lives. Second language acquisition plays an important role in the lives of the students, and this acquisition should be a pleasant one and should not become a burden for the students. Hence, it is the primary duty of the teachers to weed out any wrong notions in the minds of the students with regard to language learning. The teacher should also understand the importance of the psychological health of the students and plan their curriculum accordingly. As the techniques of psychoanalysis are not very complicated and as it involves talk therapy, which comes easily to teachers, teachers should be able to engage psychoanalysis in their classroom setting. A healthy mind with a positive attitude will always be open to any new ideas, will accept reality and can develop resiliency to handle problems according to the situation. 


\title{
International Advanced Research Journal in Science, Engineering and Technology
}

\author{
Vol. 8, Issue 9, September 2021
}

DOI: $10.17148 /$ IARJSET.2021.8937

\section{REFERENCES}

[1] (Wickramaratne et al., 1989). Seligman, Martin EP, Randal M. Ernst, Jane Gillham, Karen Reivich, and Mark Linkins. "Positive education: Positive psychology and classroom interventions." Oxford review of education 35, no. 3 (2009): 293-311.

[2] Ekstein, Rudolf. "Psychoanalysis and education for the facilitation of positive human qualities." Journal of Social Issues 28, no. 3 (1972): $71-85$.

[3] "“Always Look At The Bright Side Of Life?":"Positive” Psychology, Psychoanalysis, And Pastoral Theology." Journal of Pastoral Theology 24, no. 2 (2014): 3-1

[4] "“Always Look At The Bright Side Of Life?":"Positive” Psychology, Psychoanalysis, And Pastoral Theology." Journal of Pastoral Theology 24, no. 2 (2014): 3-1.

[5] Reclaiming the positive in psychoanalytic psychotherapy." British Journal of Psychotherapy 25, no. 4 (2009): $435-455$.

[6] Music, Graham. "What has psychoanalysis got to do with happiness? Reclaiming the positive in psychoanalytic psychotherapy." British Journal of Psychotherapy 25, no. 4 (2009): 435-455

\section{BIBLIOGRAPHY}

1. Ushioda, Ema, ed. International perspectives on motivation: Language learning and professional challenges. Springer, 2013.

2. $\quad$ Farrell, Thomas SC. "Learning to teach English language during the first year: Personal influences and challenges." Teaching and Teacher Education 19, no. 1 (2003): 95-111.

3. Banegas, Darío Luis. "Integrating content and language in English language teaching in secondary education: Models, benefits, and challenges." Studies in Second Language Learning and Teaching 2, no. 1 (2012): 111-136.

4. Taubman, Peter Maas. Disavowed knowledge: Psychoanalysis, education, and teaching. Routledge, 2012.

5. $\quad$ Felman, Shoshana. "Psychoanalysis and education: Teaching terminable and interminable." Yale French Studies 63 (1982): $21-44$.

6. $\quad$ Arrivé, Michel. "Linguistics and psychoanalysis." Trans. James Leader. Amsterdam/Philadelphia: Benjamins (1992).

7. Music, Graham. "What has psychoanalysis got to do with happiness? Reclaiming the positive in psychoanalytic psychotherapy." British Journal of Psychotherapy 25, no. 4 (2009): 435-455

8. $\quad$ Verdugo, Víctor Corral. "The positive psychology of sustainability." Environment, Development and Sustainability 14, no. 5 (2012): 651666.

9. $\quad$ Bozkurt, Beyhan, and Nausheen Pasha-Zaidi. "The Contribution of Psychoanalysis to a Positive Islamic Psychology." In Toward a Positive Psychology of Islam and Muslims, pp. 381-398. Springer, Cham, 2021.

10. $\quad$ Emde, Robert, N. "Positive emotions for psychoanalytic theory: Surprises from infancy research and new directions." Journal of the American Psychoanalytic Association 39 (1991): 5-44.

11. Luthar, Suniya S., Emily L. Lyman, and Elizabeth J. Crossman. "Resilience and positive psychology." In Handbook of developmental psychopathology, pp. 125-140. Springer, Boston, MA, 2014.

12. Yates, Tuppett M., and Ann S. Masten. "Fostering the future: Resilience theory and the practice of positive psychology." (2004).

13. Yates, Tuppett M., Fanita A. Tyrell, and Ann S. Masten. "Resilience theory and the practice of positive psychology from individuals to societies." Positive psychology in practice: Promoting human flourishing in work, health, education, and everyday life (2015): 773-788.

14. Lemay, Raymond, and Hayat Ghazal. "Resilience and positive psychology: Finding hope." Child \& Family 5, no. 1 (2001): 10-21.

15. Madhumidha V.; Harshini P.. "The importance of English Literature in the restoration of Culture". International Research Journal on Advanced Science Hub, 3, Special Issue ICARD-2021 3S, 2021, 162-166. doi: 10.47392/irjash.2021.086 